\title{
Absence of Survival Improvement for Patients with Esthesioneuroblastoma Over the Past Two Decades: A Population-based Study
}

Huy Gia Vuong ( $\square$ huyvuong@hotmail.com )

The University of Oklahoma Health Sciences Center https://orcid.org/0000-0001-6213-765X

\section{Duy Duc Nguyen}

Cho Ray Hospital: Benh vien Cho Ray

\section{Edward El-Rassi}

The University of Oklahoma Health Sciences Center

Tam N. M. Ngo

Pham Ngoc Thach University of Medicine

lan F. Dunn

The University of Oklahoma Health Sciences Center

\section{Research Article}

Keywords: Esthesioneuroblastoma (ENB), sinonasal tract, Surveillance, Epidemiology

Posted Date: June 10th, 2021

DOl: https://doi.org/10.21203/rs.3.rs-600525/v1

License: (9) This work is licensed under a Creative Commons Attribution 4.0 International License. Read Full License 


\section{Abstract}

Introduction: Esthesioneuroblastoma (ENB) is a rare malignancy of the sinonasal tract and its infrequency has confounded efforts at clearly describing the survival trends associated with this neoplasm over the years. In this study, we studied survival trends in ENB and investigated the impact of treatment extent and modality on patient outcomes.

Methods: We accessed the Surveillance, Epidemiology, and End Result (SEER) program to identify ENB cases from 1998 to 2016. A Chi-square test was used to compare the categorical covariates whereas a ttest or Mann-Whitney $\mathrm{U}$ test was utilized for continuous variables. The impact of prognostic factors on survival was computed using a Kaplan-Meier analysis and multivariate Cox proportional hazards model. We divided ENB patients into four periods including 1998-2002, 2003-2007, 2008-2012, and 2013-2016, and investigated survival trends using the Kaplan-Meier curve and log-rank test.

Results: ENB patients who underwent biopsy alone were associated with older age, larger tumor diameter, increased rates of tumor extension, nodal/distant metastases, and advanced stages as compared to patients undergoing tumor resection. Our results also demonstrated that surgical resection and adjuvant radiotherapy could confer survival advantages whereas chemotherapy was associated with reduced survival in patients with ENB. Over the past two decades, surprisingly, there has been no change in survival rates for patient with ENB $(p=0.793)$.

Conclusion: Despite advanced diagnostic studies and modernized treatment approaches, ENB survival has remained unchanged over the years, calling for improved efforts to develop appropriate individualized interventions for this rare tumor entity. Our results also confirmed that surgery and adjuvant radiotherapy is associated with improved patient survival whereas the use of chemotherapy should be considered carefully.

\section{Introduction}

Esthesioneuroblastoma (ENB) is a rare sinonasal malignancy originating from the olfactory epithelium; other descriptive terms have also been associated with this entity including olfactory neuroblastoma, olfactory placode tumor, esthesioneurocytoma, or esthesioneuroma [1, 2]. ENBs account for 3-6\% of all malignant neoplasms of the sinonasal tract with a bimodal distribution primarily affecting adolescents/young adults and patients around 50 years of age [3]. ENB usually invades locoregionally but may also metastasize to remote locations [4].

Prognostic factors for overall survival (OS) of ENB patients include age at diagnosis, Kadish stage, Hyams grade, TNM staging, and use of radiotherapy [4-6]. Surgical resection is usually the primary treatment for ENB; however, advanced stage of disease at presentation is common and may blunt the efficacy of aggressive surgery [7]. While surgery alone or the combination of surgery and radiation may confer good outcomes in low- and intermediate-risk patients, the role of tumor resection and adjuvant therapies in higher-risk groups is controversial. The survival trends of nasal cavity malignancies such as 
squamous cell carcinoma and undifferentiated carcinoma have been outlined, but less is known regarding the survival trend of ENBs over the past 2 decades [8-10]. The purpose of this study was to examine the survival trend of ENB patients using the Surveillance, Epidemiology, End Result (SEER) database. Additionally, the impact of treatment extent and modality on survival outcomes was also investigated.

\section{Materials And Methods Patient selection}

We accessed the SEER database for patients with ENB from 1998 to 2016. The year 1998 was selected as the first year of this study because extent of resection (EOR) data was tabulated in SEER from this year onward. Patients who were diagnosed at autopsy or with death certificate only, those with missing treatment field information (EOR, radiotherapy, and chemotherapy), or those with unknown follow-up were excluded from the analysis. We also removed two cases of ENB arising in the upper lobe of the lung and adrenal gland. A total of 733 ENB cases were identified for data analysis.

\section{Statistical analyses}

In the SEER registry, EOR was characterized as gross total resection (GTR), subtotal resection (STR), or biopsy. The baseline characteristics of patients with ENB were compared using Chi-square test and Fisher's exact test for categorical variables and Student t-test or Wilcoxon rank-sum test for continuous covariates, as appropriate. We performed the log-rank test and multivariate Cox proportional hazards model to assess the impact of treatment covariates and other demographic/clinical parameters on OS. Proportionality assumptions of the Cox regression models were determined by log-log survival curves and with the use of Schoenfeld residuals. We estimated the deviance residuals and the DFBETA values to examine influential observations.

To evaluate the survival trend of patients with ENB, four distinct periods were examined as follows: 1998-2002, 2003-2007, 2008-2012, and 2013-2016. The 1-, 3-, and 5-year survival rates of the entire population and subgroups stratified by EOR were calculated. Trend analysis was performed using the logrank test and Kaplan-Meier curves. All p-values were two-sided, with significance defined by a threshold of 0.05. Statistical analyses were conducted using IBM SPSS Statistics for Windows, version 22.0 (IBM Corp., Armonk, N.Y., USA) and R software, version 3.6.1 (The R Foundation, Vienna, Austria).

\section{Result}

\section{The characteristics of ENB patients stratified by EOR}

Table 1 shows the characteristics of 733 patients with ENB, who were subsequently separated into groups by extent of resection (biopsy, STR, and GTR). The median age of patients with ENB was 54 years old with a male predilection. The median tumor size was $44 \mathrm{~mm}$ with the largest tumor size found in the 
biopsy EOR group. Stratified by SEER staging, tumors in the biopsy EOR group were associated with increased patient age, greater tumor extension, presence of nodal and/or distant metastases, and advanced SEER stage $(p<0.001)$. 
Table 1

Characteristics of ENB patients stratified by EOR

\begin{tabular}{|c|c|c|c|c|c|}
\hline Parameters & All & Biopsy & $\begin{array}{l}\text { Subtotal } \\
\text { resection }\end{array}$ & $\begin{array}{l}\text { Gross total } \\
\text { resection }\end{array}$ & $\begin{array}{l}\mathrm{p}- \\
\text { value }\end{array}$ \\
\hline Patient no. (\%) & 733 & $\begin{array}{l}119 \\
(16.3)\end{array}$ & $366(49.9)$ & $248(33.8)$ & \\
\hline Age, median (IQR) (yrs) & $\begin{array}{l}54(44- \\
64)\end{array}$ & $\begin{array}{l}61(49- \\
76)\end{array}$ & $54(42-64)$ & $51(44-61)$ & $\dot{0} 001$ \\
\hline Gender, no. (\%) & & & & & 0.073 \\
\hline Female & $\begin{array}{l}316 \\
(43.1)\end{array}$ & $45(37.8)$ & $173(47.3)$ & $98(39.5)$ & \\
\hline Male & $\begin{array}{l}417 \\
(56.9)\end{array}$ & $74(62.2)$ & $193(52.7)$ & $150(60.5)$ & \\
\hline Race, no. (\%) & & & & & 0.222 \\
\hline White & $\begin{array}{l}578 \\
(79.6)\end{array}$ & $87(73.7)$ & $293(80.7)$ & $198(80.8)$ & \\
\hline Non-white & $\begin{array}{l}148 \\
(20.4)\end{array}$ & $31(26.3)$ & $70(19.3)$ & $47(19.2)$ & \\
\hline $\begin{array}{l}\text { Tumor size, median (IQR) } \\
(\mathrm{mm})\end{array}$ & $\begin{array}{l}44(30- \\
57)\end{array}$ & $\begin{array}{l}57(46- \\
63)\end{array}$ & $40(30-52)$ & $45(29-55)$ & $\dot{0} 001$ \\
\hline Tumor extension, no. (\%) & & & & & $\dot{0} 001$ \\
\hline T1 & $\begin{array}{l}106 \\
(21.9)\end{array}$ & $4(6.0)$ & $79(31.0)$ & $23(14.2)$ & \\
\hline T2 & $46(9.5)$ & $5(7.5)$ & $27(10.6)$ & $14(8.6)$ & \\
\hline T3 & $\begin{array}{l}110 \\
(22.7)\end{array}$ & $15(22.4)$ & $54(21.2)$ & $41(25.3)$ & \\
\hline T4 & $\begin{array}{l}222 \\
(45.9)\end{array}$ & $43(64.2)$ & $95(37.3)$ & $84(51.9)$ & \\
\hline Nodal involvement, no. (\%) & & & & & $\dot{0} 001$ \\
\hline NO & $\begin{array}{l}431 \\
(89.8)\end{array}$ & $54(75.0)$ & $235(95.1)$ & $142(88.2)$ & \\
\hline $\mathrm{N} 1$ & $49(10.2)$ & $18(25.0)$ & $12(4.9)$ & $19(11.8)$ & \\
\hline $\begin{array}{l}\text { DM at presentation, no. } \\
(\%)\end{array}$ & & & & & $<.001$ \\
\hline
\end{tabular}

Abbreviations: DM, distant metastasis; IQR, interquartile range; SEER, Surveillance, Epidemiology, and End Result 


\begin{tabular}{|c|c|c|c|c|c|}
\hline Parameters & All & Biopsy & $\begin{array}{l}\text { Subtotal } \\
\text { resection }\end{array}$ & $\begin{array}{l}\text { Gross total } \\
\text { resection }\end{array}$ & $\begin{array}{l}\mathrm{p}- \\
\text { value }\end{array}$ \\
\hline MO & $\begin{array}{l}482 \\
(97.4)\end{array}$ & $65(90.3)$ & $257(99.2)$ & $160(97.6)$ & \\
\hline M1 & $13(2.6)$ & $7(9.7)$ & $2(0.8)$ & $4(2.4)$ & \\
\hline $\begin{array}{l}\text { SEER historic stages, no. } \\
(\%)\end{array}$ & & & & & $<.001$ \\
\hline Localized & $\begin{array}{l}157 \\
(22.8)\end{array}$ & $10(9.1)$ & $108(31.5)$ & $39(16.5)$ & \\
\hline Regional & $\begin{array}{l}270 \\
(39.1)\end{array}$ & $40(36.4)$ & $129(37.6)$ & $101(42.6)$ & \\
\hline Distant & $\begin{array}{l}231 \\
(33.5)\end{array}$ & $50(45.5)$ & $91(26.5)$ & $90(38.0)$ & \\
\hline Unstaged & $32(4.6)$ & $10(9.1)$ & $15(4.4)$ & $7(3.0)$ & \\
\hline Radiotherapy & & & & & $<.001$ \\
\hline No & $\begin{array}{l}204 \\
(27.8)\end{array}$ & $44(37.0)$ & $114(31.1)$ & $46(18.5)$ & \\
\hline Yes & $\begin{array}{l}529 \\
(72.2)\end{array}$ & $75(63.0)$ & $252(68.9)$ & $202(81.5)$ & \\
\hline Chemotherapy & & & & & $\begin{array}{l}<.001 \\
0.00\end{array}$ \\
\hline No & $\begin{array}{l}500 \\
(68.2)\end{array}$ & $52(43.7)$ & $273(74.6)$ & $175(70.6)$ & \\
\hline Yes & $\begin{array}{l}233 \\
(31.8)\end{array}$ & $67(56.3)$ & $93(25.4)$ & $73(29.4)$ & \\
\hline Patient survival, no. (\%) & & & & & $\hat{0}_{0.001}$ \\
\hline Alive & $\begin{array}{l}483 \\
(65.9)\end{array}$ & $44(37.0)$ & $266(72.7)$ & $173(69.8)$ & \\
\hline Dead & $\begin{array}{l}250 \\
(34.1)\end{array}$ & $75(63.0)$ & $100(27.3)$ & $75(30.2)$ & \\
\hline
\end{tabular}

Radiotherapy and chemotherapy were administered in $72.2 \%$ and $31.8 \%$ of cases, respectively. Interestingly, radiotherapy was more frequently used in patients undergoing GTR whereas patients with biopsy only were more commonly subjected to chemotherapy $(p<0.001)$. About one-third of ENB patients died at the last follow-up, and the survival rates were significantly different between the three EOR groups. 
Patients in the biopsy EOR group had a higher mortality rate when compared to patients who underwent either STR or GTR.

\section{Prognostic factors of ENB patients}

Using the multivariate Cox regression model, we identified several prognostic factors that negatively affected overall survival of ENB patients (Table 2). These factors include older age, male gender, and administration of chemotherapy (Fig. 1) whereas surgical resection and adjuvant radiotherapy conferred survival advantage. Compared to GTR, patients with STR had a comparable survival $(\mathrm{HR}=0.848 ; 95 \% \mathrm{Cl}$ $=0.624-1.152 ; p=0.292)$.

Table 2

Multivariate Cox regression analysis for all-cause mortality of ENB patients

\begin{tabular}{|llll|}
\hline & Variable & Hazard Ratio $(95 \% \mathrm{Cl})$ & p-value \\
\hline Age & Per year increase & $1.032(1.023-1.042)$ & $<0.001$ \\
\hline Gender & Female & Reference & \\
\hline Mace & Non-white & $1.598(1.232-2.072)$ & $<0.001$ \\
\hline & White & Reference & \\
\hline Resection & Biopsy & $0.774(0.576-1.039)$ & 0.088 \\
\hline & STR & Reference & $<0.001$ \\
\hline GTR & $0.526(0.380-0.729)$ & 0.008 \\
\hline Radiotherapy & No & $0.621(0.436-0.883)$ & $<0.001$ \\
\hline & Yes & Reference & \\
\hline Chemotherapy & No & $0.579(0.428-0.784)$ & $<0.001$ \\
\hline & Yes & Reference & \\
\hline Abbreviations: Cl, confidence interval; GTR, gross total resection; STR, subtotal resection
\end{tabular}

In ENB patients with advanced SEER stages (regional and distant metastases), we observed similar prognostic factors to the overall ENB population (Table S1).

\section{Survival trend of ENB patients over time}

The survival rates of ENB patients in different periods are presented in Table 3. In general, there were no significant improvements in the survival trend of ENB patients during the study period 1998-2016 (logrank test, $p=0.793)$ (Fig. 2). 
Table 3

The 1-, 3-, and 5-year survival rate of ENB patients in different periods

\begin{tabular}{|c|c|c|c|c|}
\hline \multirow[t]{2}{*}{ Period } & \multirow[t]{2}{*}{ Extent of resection } & \multicolumn{3}{|c|}{ Survival rate (\%) } \\
\hline & & 1-year & 3-year & 5-year \\
\hline \multirow[t]{4}{*}{ 1998-2002 } & Biopsy & 69.0 & 51.7 & 37.9 \\
\hline & STR & 93.2 & 81.4 & 74.6 \\
\hline & GTR & 98.1 & 90.4 & 75.0 \\
\hline & Overall & 88.6 & 78.6 & 67.1 \\
\hline \multirow[t]{4}{*}{$2003-2007$} & Biopsy & 70.3 & 56.8 & 48.6 \\
\hline & STR & 95.5 & 87.7 & 84.2 \\
\hline & GTR & 92.0 & 81.3 & 77.3 \\
\hline & Overall & 89.6 & 79.6 & 75.1 \\
\hline \multirow[t]{4}{*}{$2008-2012$} & Biopsy & 72.0 & 52.0 & 48.0 \\
\hline & STR & 89.6 & 78.4 & 76.5 \\
\hline & GTR & 95.0 & 89.9 & 82.8 \\
\hline & Overall & 89.1 & 78.5 & 74.9 \\
\hline \multirow[t]{4}{*}{$2013-2016$} & Biopsy & 69.5 & 38.2 & NA \\
\hline & STR & 95.1 & 87.2 & NA \\
\hline & GTR & 94.4 & 86.5 & NA \\
\hline & Overall & 91.0 & 78.6 & NA \\
\hline
\end{tabular}

\section{Discussion}

Standardized treatment for ENB has not been well established due to the relative rarity of these tumors and associated lack of clinical trials. Surgical resection is generally accepted as first line treatment in the care of ENB patients [11] and the attainment of negative margins is an independent prognostic factors for improved survival $[4,12,13]$. In recent years, endoscopic endonasal techniques have been increasingly used, and some series have reported an improvement in OS and progression-free survival in ENB patients undergoing an endoscopic endonasal craniofacial resection as compared to the traditional open craniofacial resection $[11,14]$. Regardless of approach, it is challenging to attain a gross total resection and negative surgical margins in ENB patients due to the locoregional extension of the tumor and complex neurovascular anatomy of the anterior cranial base [15]. Our findings confirmed that GTR could 
only be obtained in one-third of patients and $16 \%$ of patients had tumor biopsies only. Furthermore, large tumor size, tumor extension, nodal, and distant metastases at presentation may affect the success of surgical eradication. Morita et al. showed that GTR offers more survival benefits than STR and biopsy [16]; however, our results indicate that GTR and STR added survival advantage to ENB patients as compared to patients managed nonoperatively but there was no survival difference between GTR and STR (Fig. 1).

ENB is known to be radiosensitive and radiotherapy plays an important role in ENB management $[11,17]$ which was further confirmed in this study. It is most commonly used in the adjuvant setting to mitigate recurrence risk following surgery but has also been described in the neoadjuvant setting to reduce tumor burden prior to surgery or even as sole therapy with or without chemotherapy in patients with unresectable disease. [12,14,17-21]. In our study, radiotherapy was performed in about two-thirds of patients with biopsy alone and STR, which is lower than the GTR group. Of note, it may be difficult to orient surgical sinonasal specimens, complicating pathologic examination of the surgical margins. Because of uncertain resection margin status, postoperative radiation treatment seems justified in all patients to minimize the risk of locoregional relapse. Furthermore, while a combination of surgery and radiation yields the best outcome in low- and intermediate-risk patients [18], the treatment algorithm for advanced cases has not been well established. [19, 21, 22].

Several studies have suggested a survival benefit of chemotherapy in ENBs, especially in high-grade tumors [20,23-25]. Also, preoperative chemotherapy might be effective for tumor reduction and improving surgical resection, especially in advanced diseases [21, 22, 26]. However, the use of chemotherapy in ENB patients may also increase mortality risk $[20,27,28]$. Our study also demonstrated a negative effect of chemotherapy regardless of tumor stage, which is in line with previous studies [20, 29]. While chemotherapy is not routinely recommended in the treatment for ENB it is important to consider the possibility of confounding variables such as selection bias for very advanced or aggressive disease. Ultimately, its role should be further examined alongside important parameters such as the Kadish staging, Dulguerov's modified TNM staging, and Hyams grading systems, which are missing in the SEER database.

The survival rates of carcinomas of the nasal cavity and paranasal sinuses have been improved over the years with the developments of new techniques for early diagnoses and advanced treatment modalities $[10,30-32]$. However, our study indicated that there has been no improvement in the survival of ENB patients over the last 20 years. As mentioned, obtaining negative margins is one of the vital prognostic factors for ENB survival $[15,27,33]$ and despite the introduction of new surgical techniques and improved visualization using endoscopic endonasal techniques, it is still challenging to achieve margin-negative resections, either macroscopically or microscopically. This is largely a result of patients with ENB presenting with advanced stage of disease at diagnosis due to a relative paucity of symptoms early on in addition to diagnostic delays from attributing early symptoms to 'allergies' or 'sinusitis'. In fact, up to $62 \%$ of patients with ENB have advanced stage disease (Kadish stage $C$ and D) [16] at diagnosis. Taken together, ENB is a difficult tumor to clinically diagnose at early stages and there is little consensus on 
standard of care for this rare tumor entity, especially for high-risk individuals given the lack of large prospective cohort studies or clinical trials resulting in heterogenenous care across treatment centers and over time which may help explain the lack of survival improvement over the past two decades.

There are limitations of our study that need to be discussed. Firstly, several important markers of ENB are not included in the SEER program including Kadish staging, Dulguerov's modified TNM staging, Hyams grading, surgical margins, surgical approach, and chemoradiotherapy regimens. Some of these factors contribute to whether or not a lesion is resectable which would help explain why certain patients underwent a biopsy alone and/or any selection bias for administration of chemotherapy. Next, patients undergoing STR or GTR may share different characteristics related to their age, performance status, and medical comorbidities than those who had biopsy only, which could contribute to survival differences. There are also very likely to be other biological tumor heterogeneities in this patient population.

In conclusion, our study demonstrates the utility of surgical resection followed by adjuvant radiotherapy in improving survival of ENB patients, whereas the role of chemotherapy remains somewhat unclear in this study population. Despite the evolution of diagnostic and treatment methods, there was no remarkable survival improvement of ENB patients over the past two decades, highlighting an urgent need to refine the standards of care for these patients and identify new therapeutic targets.

\section{Declarations}

\section{Ethics approval and consent to participate}

Not applicable

\section{Consent for publication}

Not applicable

\section{Availability of data and material}

Not applicable

\section{Competing interest}

The authors declare no conflicts of interest.

\section{Funding}

This study received no funding support 


\section{Authors' contributions}

HGV: conceptualization, data curation, formal analysis, investigation, methodology, project administration, software, validation, writing original, writing-review, and editing. DDN: writing-original, writing-review, and editing EE: writing-original, writing-review, and editing TNMN: data curation, formal analysis, investigation, methodology, writing-review. IFD: project administration, validation, writing-review, editing, and supervision. All authors have read and approved the manuscript.

\section{Acknowledgments}

Not applicable

\section{References}

1. Kumar R (2015) Esthesioneuroblastoma: Multimodal management and review of literature. World J Clin Cases 3:774-778. doi:10.12998/wjcc.v3.i9.774

2. Fletcher CDM (2013) Diagnostic histopathology of tumors. Churchill Livingstone

3. Ostrom QT, Gittleman H, Liao P, Vecchione-Koval T, Wolinsky Y, Kruchko C, Barnholtz-Sloan JS (2017) CBTRUS Statistical Report: Primary brain and other central nervous system tumors diagnosed in the United States in 2010-2014. Neurooncology 19:v1-v88. doi:10.1093/neuonc/nox158

4. Jethanamest D, Morris LG, Sikora AG, Kutler DI (2007) Esthesioneuroblastoma: a population-based analysis of survival and prognostic factors. Archives of otolaryngology-head neck surgery 133:276280. doi:10.1001/archotol.133.3.276

5. Dias FL, Sa GM, Lima RA, Kligerman J, Leoncio MP, Freitas EQ, Soares JR, Arcuri RA (2003) Patterns of failure and outcome in esthesioneuroblastoma. Archives of otolaryngology-head neck surgery 129:1186-1192. doi:10.1001/archotol.129.11.1186

6. Vuong HG, Ngo TNM, Dunn IF (2021) Consolidating the Hyams grading system in esthesioneuroblastoma - an individual participant data meta-analysis. Journal of neuro-oncology. doi:10.1007/s11060-021-03746-2

7. Thompson L (2006) Olfactory neuroblastoma. Ear, nose. \& throat journal 85:569-570

8. Sanghvi S, Khan MN, Patel NR, Yeldandi S, Baredes S, Eloy JA (2014) Epidemiology of sinonasal squamous cell carcinoma: a comprehensive analysis of 4994 patients. Laryngoscope 124:76-83. doi:10.1002/lary.24264

9. Chambers KJ, Lehmann AE, Remenschneider A, Dedmon M, Meier J, Gray ST, Lin DT (2015) Incidence and survival patterns of sinonasal undifferentiated carcinoma in the United States. Journal of neurological surgery Part B Skull base 76:94-100. doi:10.1055/s-0034-1390016

10. Turner JH, Reh DD (2012) Incidence and survival in patients with sinonasal cancer: a historical analysis of population-based data. Head Neck 34:877-885. doi:10.1002/hed.21830 
11. Fiani B, Quadri SA, Cathel A, Farooqui M, Ramachandran A, Siddiqi I, Ghanchi H, Zafar A, Berman BW, Siddiqi J (2019) Esthesioneuroblastoma: A Comprehensive Review of Diagnosis, Management, and Current Treatment Options. World neurosurgery 126:194-211. doi:10.1016/j.wneu.2019.03.014

12. Mehta GU, Raza SM, Su SY, Hanna EY, DeMonte F (2020) Management of olfactory neuroblastoma, neuroendocrine carcinoma, and sinonasal undifferentiated carcinoma involving the skullbase. Journal of neuro-oncology 150:367-375. doi:10.1007/s11060-020-03537-1

13. Harvey RJ, Nalavenkata S, Sacks R, Adappa ND, Palmer JN, Purkey MT, Schlosser RJ, Snyderman C, Wang EW, Woodworth BA, Smee R, Havas T, Gallagher R (2017) Survival outcomes for stagematched endoscopic and open resection of olfactory neuroblastoma. Head Neck 39:2425-2432. doi:10.1002/hed.24912

14. Li R, Tian S, Zhu Y, Yan L, Zhu W, Quan H, Wang S (2019) Management of orbital invasion in esthesioneuroblastoma: 14 years' experience. Radiat Oncol 14:107. doi:10.1186/s13014-019-1313-1

15. Patel S, Singh B, Stambuk H, Carlson D, Bridger G, Cantu G, Cheesman A, Donald P, Fliss D, Gullane P, Kamata S-E, Janecka I, Kowalski L, Kraus D, Levine P, Medina L, Pradhan S, Schramm V, Snyderman C, Shah J (2012) Craniofacial Surgery for Esthesioneuroblastoma: Report of an International Collaborative Study. Journal of neurological surgery Part B Skull base 73:208-220. doi:10.1055/s0032-1311754

16. Morita A, Ebersold MJ, Olsen KD, Foote RL, Lewis JE, Quast LM (1993) Esthesioneuroblastoma: prognosis and management. Neurosurgery 32:706-714. doi:10.1227/00006123-199305000-00002 discussion $714-705$

17. Platek ME, Merzianu M, Mashtare TL, Popat SR, Rigual NR, Warren GW, Singh AK (2011) Improved survival following surgery and radiation therapy for olfactory neuroblastoma: analysis of the SEER database. Radiat Oncol 6:41. doi:10.1186/1748-717X-6-41

18. Dulguerov P, Allal AS, Calcaterra TC (2001) Esthesioneuroblastoma: a meta-analysis and review. The Lancet Oncology 2:683-690. doi:10.1016/s1470-2045(01)00558-7

19. Fernström E, Nyman J, Hammerlid E, Holmberg E, Haugen-Cange H, Petruson K, Abel E, BjörkEriksson T (2017) Results of preoperative chemoradiotherapy for patients with advanced cancer of the nasal cavity and paranasal sinuses. Acta oto-laryngologica 137:1292-1300. doi:10.1080/00016489.2017.1357081

20. Cranmer LD, Chau B, Rockhill JK, Ferreira M Jr, Liao JJ (2020) Chemotherapy in Esthesioneuroblastoma/Olfactory Neuroblastoma: An Analysis of the Surveillance Epidemiology and End Results (SEER) 1973-2015 Database. Am J Clin Oncol 43:203-209. doi: $10.1097 /$ coc. 0000000000000649

21. Polin RS, Sheehan JP, Chenelle AG, Munoz E, Larner J, Phillips CD, Cantrell RW, Laws ER Jr, Newman SA, Levine PA, Jane JA (1998) The role of preoperative adjuvant treatment in the management of esthesioneuroblastoma: the University of Virginia experience. Neurosurgery 42:1029-1037. doi:10.1097/00006123-199805000-00045 
22. Bartel R, Gonzalez-Compta X, Cisa E, Cruellas F, Torres A, Rovira A, Manos M (2018) Importance of neoadjuvant chemotherapy in olfactory neuroblastoma treatment: Series report and literature review. Acta otorrinolaringologica espanola 69:208-213. doi:10.1016/j.otorri.2017.07.001

23. Su SY, Bell D, Ferrarotto R, Phan J, Roberts D, Kupferman ME, Frank SJ, Fuller CD, Gunn GB, Kies MS, Glisson BS, Hanna EY (2017) Outcomes for olfactory neuroblastoma treated with induction chemotherapy. Head Neck 39:1671-1679. doi:10.1002/hed.24822

24. Kane AJ, Sughrue ME, Rutkowski MJ, Aranda D, Mills SA, Buencamino R, Fang S, Barani IJ, Parsa AT (2010) Posttreatment prognosis of patients with esthesioneuroblastoma. Journal of neurosurgery 113:340-351. doi:10.3171/2010.2.jns091897

25. McElroy EA Jr, Buckner JC, Lewis JE (1998) Chemotherapy for advanced esthesioneuroblastoma: the Mayo Clinic experience. Neurosurgery 42: 1023-1027; discussion 1027-1028 doi:10.1097/00006123-199805000-00040

26. Kim DW, Jo YH, Kim JH, Wu HG, Rhee CS, Lee CH, Kim TY, Heo DS, Bang YJ, Kim NK (2004) Neoadjuvant etoposide, ifosfamide, and cisplatin for the treatment of olfactory neuroblastoma. Cancer 101:2257-2260. doi:10.1002/cncr.20648

27. Carey RM, Godovchik J, Workman AD, Kuan EC, Parasher AK, Chen J, Palmer JN, Adappa ND, Newman JG, Brant JA (2017) Patient, disease, and treatment factors associated with overall survival in esthesioneuroblastoma. International forum of allergy rhinology 7:1186-1194. doi:10.1002/alr.22027

28. Alotaibi HA, Priola SM, Bernat A-L, Farrash F (2019) Esthesioneuroblastoma: Summary of Singlecenter Experiences with Focus on Adjuvant Therapy and Overall Survival. Cureus 11:e4897-e4897. doi:10.7759/cureus.4897

29. Marinelli JP, Janus JR, Van Gompel JJ, Link MJ, Foote RL, Lohse CM, Price KA, Chintakuntlawar AV (2018) Esthesioneuroblastoma with distant metastases: Systematic review \& meta-analysis. Head Neck 40:2295-2303. doi:https://doi.org/10.1002/hed.25209

30. Arruebo M, Vilaboa N, Sáez-Gutierrez B, Lambea J, Tres A, Valladares M, González-Fernández A (2011) Assessment of the evolution of cancer treatment therapies. Cancers 3:3279-3330. doi:10.3390/cancers3033279

31. Thorup C, Sebbesen L, Danø H, Leetmaa M, Andersen M, Buchwald C, Kristensen CA, Bentzen J, Godballe C, Johansen J, Grau C (2010) Carcinoma of the nasal cavity and paranasal sinuses in Denmark 1995-2004. Acta oncologica (Stockholm Sweden) 49:389-394. doi:10.3109/02841860903428176

32. Dulguerov P, Jacobsen MS, Allal AS, Lehmann W, Calcaterra T (2001) Nasal and paranasal sinus carcinoma: are we making progress? A series of 220 patients and a systematic review. Cancer 92: 3012-3029 doi:10.1002/1097-0142(20011215)92:12<3012::aid-cncr10131>3.0.co;2-e

33. Resto VA, Eisele DW, Forastiere A, Zahurak M, Lee DJ, Westra WH (2000) Esthesioneuroblastoma: the Johns Hopkins experience. Head \& neck 22: 550-558 doi:10.1002/10970347(200009)22:6<550::aid-hed2>3.0.co;2-0

Page $13 / 15$ 
Figures

Extent of Resection — Biopsy — STR — GTR

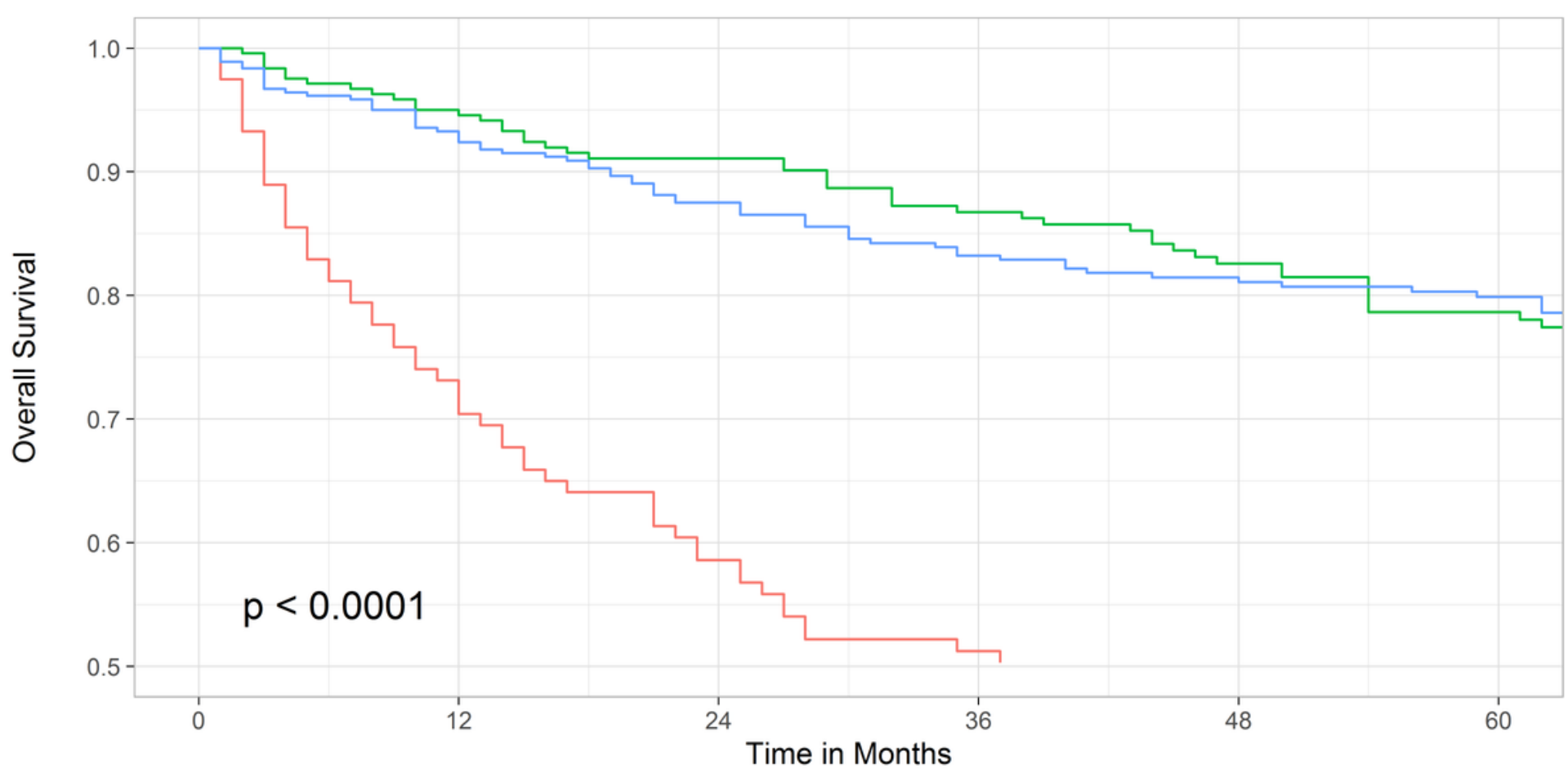

\begin{tabular}{|c|c|c|c|c|c|c|}
\hline & Numbe & & & & & \\
\hline Biopsy & 119 & 81 & 64 & 54 & 43 & 37 \\
\hline STR & 248 & 223 & 195 & 178 & 152 & 130 \\
\hline GTR & 366 & 318 & 274 & 244 & 216 & 192 \\
\hline & 0 & 12 & 24 & 36 & 48 & 60 \\
\hline
\end{tabular}

Figure 1

Kaplan-Meier curve illustrating the impact of extent of resection on ENB survival 


$$
\text { Time Periods — 1998-2002 — 2003-2007 - 2008-2012 - 2013-2016 }
$$

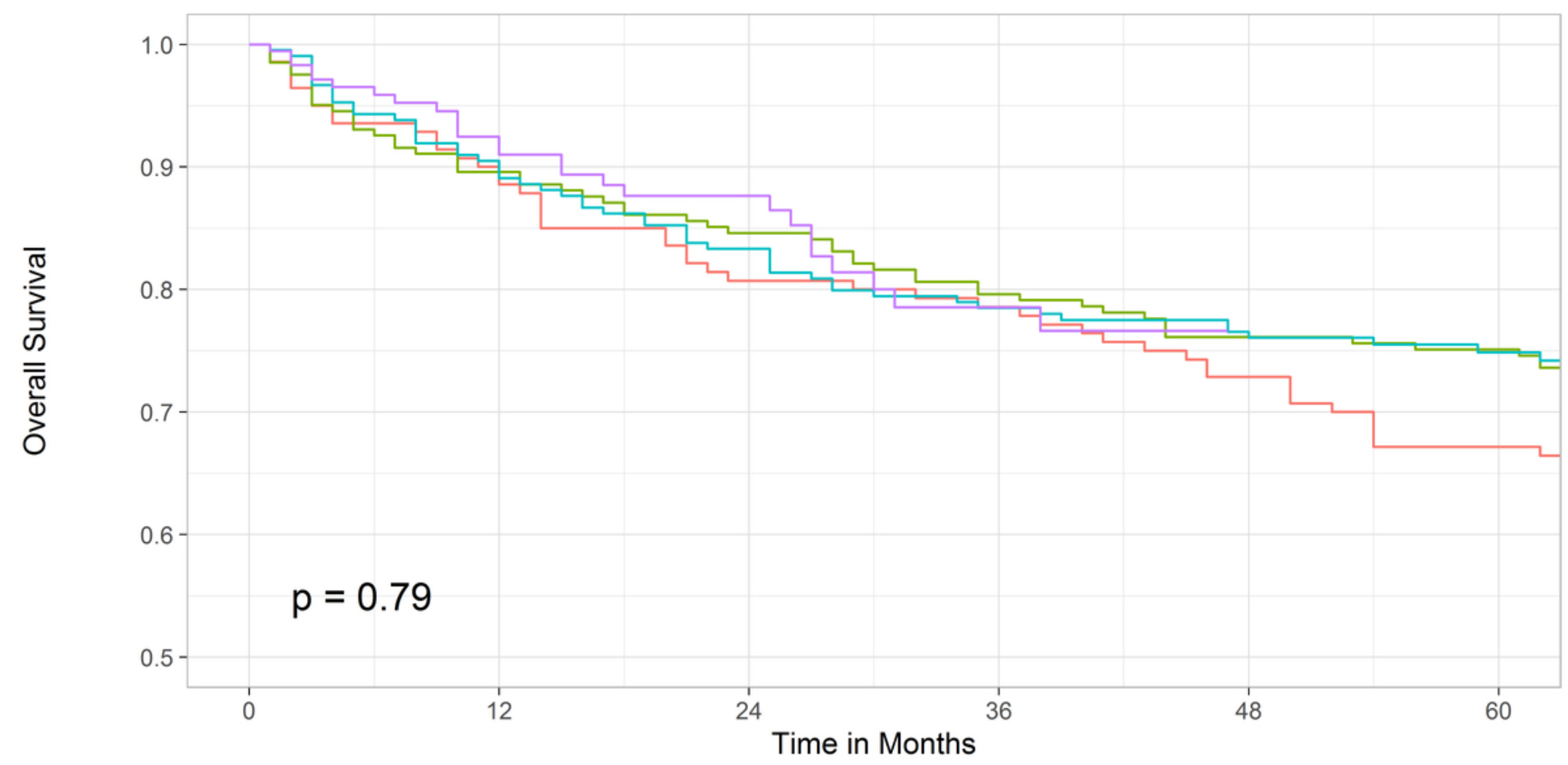

\begin{tabular}{|c|c|c|c|c|c|c|}
\hline \multirow{3}{*}{ 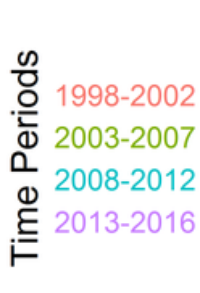 } & \multicolumn{6}{|c|}{ Number at risk } \\
\hline & $\begin{array}{l}140 \\
202 \\
211 \\
180\end{array}$ & $\begin{array}{l}126 \\
180 \\
190 \\
126\end{array}$ & $\begin{array}{c}113 \\
170 \\
173 \\
77\end{array}$ & $\begin{array}{c}110 \\
160 \\
162 \\
44\end{array}$ & $\begin{array}{c}102 \\
152 \\
157 \\
0\end{array}$ & $\begin{array}{c}94 \\
149 \\
116 \\
0\end{array}$ \\
\hline & 0 & 12 & 24 & 36 & 48 & 60 \\
\hline
\end{tabular}

Figure 2

Survival trend of ENB patients over the past two decades

\section{Supplementary Files}

This is a list of supplementary files associated with this preprint. Click to download.

- SEERENBSup.docx 